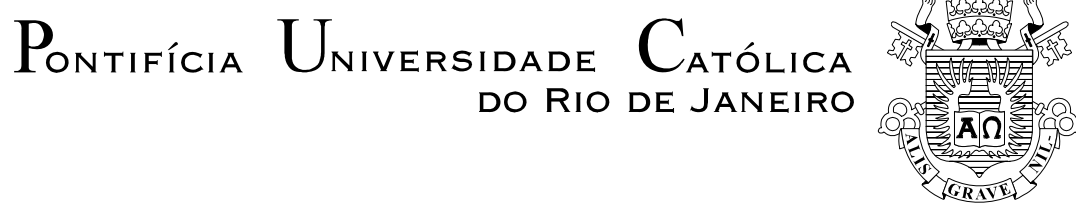

Fábio da Fonseca Moreira

\title{
O desejo de transformação em Casa na Duna,
} de Carlos de Oliveira

Dissertação de Mestrado

Dissertação apresentada ao Programa de PósGraduação em Letras do Departamento de Letras da PUC-Rio como parte dos requisitos parciais para obtenção do título de Mestre em Letras.

Orientador: Profa. Izabel Margato

Rio de Janeiro Março de 2010 


$$
\begin{array}{r}
\text { Pontifícia Universidade Católica } \\
\text { do Rio de Janeiro }
\end{array}
$$

Fábio da Fonseca Moreira

\section{O desejo de transformação em Casa na Duna, de Carlos de Oliveira}

Dissertação apresentada como requisito parcial para obtenção do grau de Mestre pelo programa de PósGraduação em Letras do Departamento de Letras do Centro de Teologia e Ciências Humanas da PUC-Rio. Aprovada pela Comissão Examinadora abaixo assinada.

Prof. Alexandre Montaury Baptista Coutinho Co-Orientador e Presidente Departamento de Letras - PUC-Rio

Prof. Ronaldo Menegaz PUC-Rio - Pesquisador Visitante/ABL

Profa. Angela Maria Thereza Lopes

UNESA

\footnotetext{
Prof. Paulo Fernando Carneiro de Andrade Coordenador Setorial do Centro de Teologia e Ciências Humanas - PUC-Rio
}

Rio de Janeiro, 22 de março de 2010. 
Todos os direitos reservados. É proibida a reprodução total ou parcial do trabalho sem autorização da universidade, do autor e do orientador.

Fábio da Fonseca Moreira

Graduou-se em Letras na UGF (Universidade Gama Filho) em 2005. Participou de vários congressos e seminários e tem artigos publicados na área de Literatura.

Ficha Catalográfica

Moreira, Fábio da Fonseca

O desejo de transformação em Casa na Duna, de Carlos de Oliveira / Fábio da Fonseca Moreira; orientadora: Izabel Margato. - 2010.

$80 \mathrm{f} . ; 30 \mathrm{~cm}$

Dissertação (Mestrado em Letras)-Pontifícia Universidade Católica do Rio de Janeiro, Rio de Janeiro, 2010.

Inclui bibliografia

1. Letras - Teses. 2. Oliveira, Carlos de. 3. Neorealismo. 4. Casa na Duna. 5. Século XX. I. Margato, Izabel. II. Pontifícia Universidade Católica do Rio de Janeiro. Departamento de Letras. III. Título. 
Para Vera, Lucas e André, os grandes amores da minha vida. 


\section{Agradecimentos}

À minha orientadora Izabel Margato, por todo apoio e estímulo e pelo cuidado primoroso, que fez com que este trabalho encontrasse a sua direção.

À Capes e à PUC-Rio, pelo apoio sem o qual este trabalho não teria se realizado.

Ao Professor Alexandre Montaury, pelo apoio e pela generosidade.

Aos Professores Ronaldo Menegaz e Angela Maria Thereza Lopes, pela gentileza com que aceitaram fazer parte da minha banca.

À Professora Cleonice Berardinelli, por sua dedicação e pelo compartilhamento carinhoso de seus profundos conhecimentos.

Aos meus colegas da PUC-Rio, especialmente ao Rodrigo Ordine e à Patrícia Botelho, companheiros memoráveis e fiéis incentivadores.

À Chiquinha e a todos os funcionários do Departamento de Letras, sempre atenciosos e dispostos a esclarecer as minhas dúvidas.

Aos meus inesquecíveis professores Jorge Vicente Valentim, Luci Ruas e José Carlos Barcellos (in memorian), pelas importantes contribuições.

Aos funcionários do Real Gabinete Português de Leitura, pelo acolhimento neste local que foi a minha segunda casa durante toda a pesquisa.

A todos os meus familiares e amigos, que sempre me estimularam e me apoiaram nas minhas escolhas.

Ao meu companheiro Marcos André, principal incentivador para a minha chegada até aqui. 


\section{Resumo}

Moreira, Fabio da Fonseca; Margato, Izabel (Orientadora). O desejo de transformação em Casa na Duna, de Carlos de Oliveira. Rio de Janeiro, 2010. 80p. Dissertação de Mestrado - Departamento de Letras, Pontifícia Universidade Católica do Rio de Janeiro.

A escrita de Carlos de Oliveira é profundamente marcada por mecanismos que particularizam o seu posicionamento como artista e intelectual comprometido com a cena política da sociedade portuguesa na segunda metade do século XX, articulando um engajamento na reflexão sobre o processo de criação literária com a sua atuação política e cultural. Dessa forma, a presente dissertação propõe identificar, com base nas questões programáticas definidas pelo movimento neorealista, o projeto de ficção do escritor Carlos de Oliveira no romance Casa na Duna e o seu propósito de estabelecer um critério de interpretação da realidade social, política e econômica da sociedade portuguesa nas primeiras décadas do século XX, estimulando uma transformação radical do homem pela transformação radical da sua vida.

\section{Palavras-Chave}

Carlos de Oliveira; Neo-realismo; Casa na Duna; século XX. 


\section{Abstract}

Moreira, Fabio da Fonseca; Margato, Izabel (Advisor). The desire of transformation in Carlos de Oliveira's Casa na Duna. Rio de Janeiro, 2010. 80p. MSc. Dissertation - Departamento de Letras, Pontifícia Universidade Católica do Rio de Janeiro.

Carlos de Oliveira's way of writing is profoundly composed by mechanisms which characterize his position as an artist and intellectual committed with the Portuguese society political scene of the middle twentieth century, articulating a reflective political engagement concerning the process of literary production regarding cultural and political actions. In this way, the following thesis aims to identify, according to the issues enhanced in the NeoRealism movement, the fictional issue raised by the Portuguese writer Carlos de Oliveira in Casa na Duna as well as his purpose of establishing some comprehension criteria in order to understand the social, the political and the economic reality of the Portuguese society in the first decades of the twentieth century, stimulating a complete transformation in men through a radical transformation in their lives.

\section{Keywords}

Carlos de Oliveira; Neo-Realism; Casa na Duna; twentieth century. 


\section{Sumário}

1. Introdução 5

2. O Neo-Realismo 9

2.1. Eclosão e propostas 9

$\begin{array}{ll}\text { 2.2. O caráter inovador } & 14\end{array}$

2.3. O "traço" polêmico 21

2.4. A elaboração estética 28

3. Carlos de Oliveira e o seu tempo 31

3.1. Um caso à parte 32

3.2. Paisagem e povoamento 36

3.3. Um operário das palavras 41

4. Casa na Duna: o desejo de transformação 44

4.1. A remodelação do romance 44

4.2. A dimensão simbólica 47

4.3. Um romance crepuscular $\quad 51$

4.4. Dramas individuais e ideologia: uma relação estreita 58

4.5. Uma versão "neo-realista" da Fatalidade 63

5. Considerações finais 69

$\begin{array}{ll}\text { 7. Referências Bibliográficas } & 71\end{array}$ 
Quantas asas pede um vôo que partiu em busca de um outro equilíbrio?

José Cardoso Pires 